\title{
ME CONVÉM LEMBRAR: TEXTO, OBJETO E PALAVRA NUMA AÇÃO NO AUTO DO MENINO DEUS - BA
}

\author{
ME CONVIENE RECORDAR: TEXTO, OBJETO Y PALABRA EN UNA \\ ACCION EN AUTO DO MENINO DEUS - BA
}

Tiago Samuel Bassani ${ }^{1}$

\begin{abstract}
Resumo: A ação descrita neste texto é derivada das pesquisas que desenvolvo atualmente, que tem como o ponto de partida as mortes que são causadas pela violência. Deste modo, ela se preocupa com o fenômeno no território nacional comparado com o cenário de outros países, sobre as quais traço diálogos com o livro de Eduardo Galeano intitulado As veias abertas da América Latina. Junto dela teço uma reflexão sobre a relação entre o texto, o objeto e a palavra numa ação performativa. $\mathrm{O}$ texto se desdobra com a descrição da ação amalgamada às reflexões emergidas dela.
\end{abstract}

Palavras-chave: Ação; palavra; objeto.

Resumen: La acción descrita en este texto se deriva de la investigación que hago actualmente, que tiene como punto de partida las muertes causadas por la violencia. Por lo tanto, le preocupa el fenómeno en el territorio nacional en comparación con el escenario de otros países, en el que trazo diálogos con el libro de Eduardo Galeano titulado Las venas abiertas de América Latina. Junto a ella reflexiono sobre la relación entre texto, objeto y palabra en una acción performativa. El texto se desarrolla con la descripción de la acción amalgamada y las reflexiones que emergen de ella.

Palabras clave: Acción; palavra; objeto.

Este texto se faz entremeado pela narrativa de uma ação ${ }^{2}$, tendo em vista as possibilidades de uma escrita também performativa que se dá no acionamento dele pela leitura, que do mesmo modo é pertencente às reflexões tecidas no desenrolar da escrita. Ele pede concessão aos protocolos para poder transcorrer pelo relato acompanhado do desígnio de um desejo, tramando conceitos, referências e desassossegos. Deste modo, apoio-me na afirmação de Paul Ricoeur que considera que "o testemunho constitui a uma estrutura fundamental de transição entre a memória e a história." (2007, p. 41).

Ainda Diana Taylor nos indaga: "Que tensões poderiam ser mostradas pelos comportamentos em performance que não seriam reconhecidas nos textos e documentos?” (2013, p. 20).

Deste modo, proponho e prossigo.

Numa tarde quente no interior da $\mathrm{Bahia}^{3}$, sentado na escadaria de uma pequena igreja chamada de Auto do Menino Deus, aguardo as pessoas que passam pelo local, convidando-as para se juntar a mim numa ação que se desenvolveria a partir de uma leitura. Ali estavam alguns estudantes, moradores das proximidades e as pessoas que zelam da igreja. A ação fazia parte de um projeto chamado Minguas de Cuerpos ${ }^{4}$, que tinha como provocação "Desobedece a la guerra", na qual minha ação contribuía com a proposição "Me convém lembrar".

\footnotetext{
${ }^{1}$ Universidade Federal do Oeste da Bahia - UFOB.

${ }^{2}$ No texto usarei a palavra ação e performance. Atento aos leitores que alguns momentos elas serão correlatas, outras não.

${ }^{3}$ Especificamente na cidade de Santa Maria da Vitória, localizada no Oeste Baiano.

${ }^{4}$ Minguas de cuerpos foi uma ação realizada em colaboração de artistas da Colômbia, México, Equador, Brasil e Camarão. Este projeto consistia em acionar/performar simultaneamente em todos os países no mesmo horário fazendo uma transmissão conjunta pela rede social em diversas plataformas. Minguas é uma tradição précolombiana de trabalho comunitário e coletivo. A referida ação teve como título "Desobedece a la guerra!. Minguas também significar trabalhar em conjunto.
} 
Depois de um pequeno ajuntamento de pessoas, todos sentados na mesma escadaria, coloco-me a ler um trecho do livro As veias abertas da América Latina de Eduardo Galeano:

\begin{abstract}
São secretas as matanças da miséria na América Latina. A cada ano, silenciosamente, sem estrépito algum, explodem três bombas de Hiroshima sobre esses povos que tem o costume de sofrer de boca calada. Essa violência sistemática, não aparente, mas real, vem aumentando: seus crimes não são noticiados pelos diários populares, mas pelas estatísticas da $\mathrm{FAO}^{5}$. Ball diz que a impunidade ainda é possível porque os pobres não podem desencadear a guerra mundial, mas o império se preocupa: incapaz de multiplicar os pães, faz o possível para suprimir os comensais. "Combata a pobreza, mate um mendigo" grafitou um mestre do humor negro num muro de La Paz. (GALEANO, 2017, p. 22).
\end{abstract}

Finalizo a leitura do trecho. Em seguida lanço uma reflexão sobre os mortos que nos são desconhecidos por meio da violência. A evidência histórica sobre o extermínio dos povos e da população pobre não pode ser um incidente, mas talvez um efeito daqueles que detém o poder na busca da manutenção de sua condição.

Manifesta-se o silêncio. Todos me olham atentos.

Posterior a indagação trago à tona as $\operatorname{lutas}^{6}$ que ocorrem no território onde nos encontramos. Não é incomum recebermos notícias sobre as comunidades e organizações de bases, que lutam pelas suas causas, em sua maioria pleiteando uma subsistência, serem mortas nas disputas em situação de desigualdade de força e poder.

Levanto-me. Retiro de dentro do livro um papel dobrado, no qual está escrito os números ${ }^{7}$ das mortes por violência no território nacional. Deixo o livro nas escadarias da igreja. Seguro apenas o papel nas mãos. Atravesso a rua de paralelepípedo. Me direciono ao cruzeiro ${ }^{8}$ que está posicionado em frente da igreja.

Coloco-me em pé, de costas para a cruz, de frente para a igreja e vou declamando os números das mortes por violência. Abaixo-me e, de cócoras, vou escrevendo os números no chão da calçada com carvão. Os movimentos são refeitos a cada número ditado: em pé pronuncio os números, de cócoras eu os inscrevo na calçada, ao pé do cruzeiro, em frente à igreja. A ação se repete até eu pronunciar todos os índices.

\footnotetext{
${ }^{5}$ A sigla FAO mencionada pelo autor diz respeito a uma agência da Organização das Nações Unidas (ONU) para empenha esforços para a erradicação da fome e para o combate à pobreza. Denomina-se por Organização das Nações Unidas para a Alimentação e a Agricultura.

${ }^{6}$ As lutas a qual me refiro são embates identificados no Território de Identidade do Rio Corrente, onde há movimentos de lutas de base da população contra empresas em defesa da terra e da água num espaço geográfico de transição do cerrado para a caatinga.

7 Números constantes do ATLAS DA VIOLÊNCIA. Relatório disponível em: <https://biblioteca.ibge.gov.br/visualizacao/periodicos/135/rc_2017_v44_informativo.pdfł >. Acesso em: 25 março 2019.

${ }^{8}$ Cruzeiro trata-se de uma cruz que neste caso foi colocada no alto de um morro.
} 


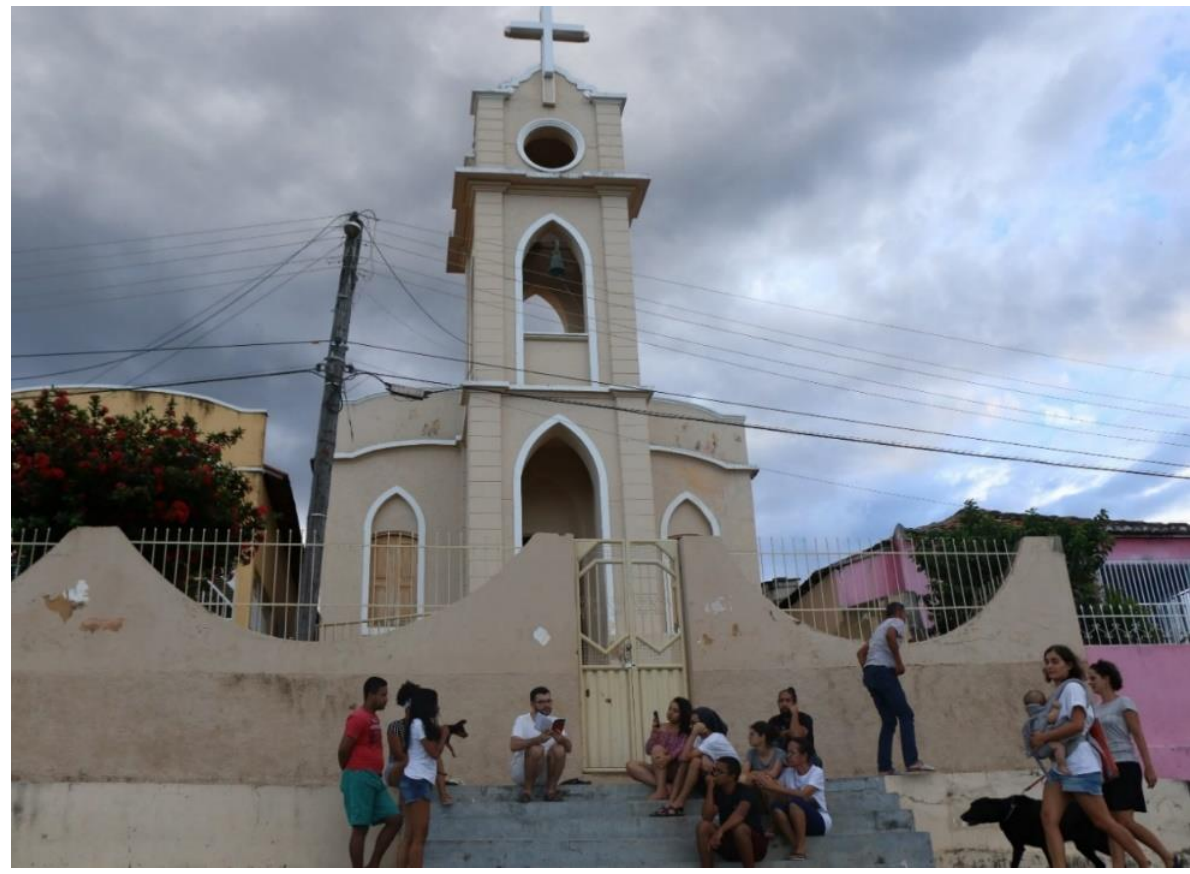

Figura 1- Tiago Bassani, Me convém lembrar, 2019 - Foto: Cirlla Machado - Fonte: Arquivo do autor

Durante a escrita no chão, eu proferia uma ladainha com os seguintes dizeres:

Não sucumbirei a dor;

Não sucumbirei a violência;

Não sucumbirei ao preconceito.

Não morrerei parado.

Viverei e morrerei na luta.

(Do autor)

Uma pausa. Retomo murmurejando:

Chaga de sol, rosácea ardente Aqueles linhos de sangue, o peito Mais profundo, aberto, extenso,

Toda a delicadez do poeta Flui Exangue

Num círculo de dor. Assim te lembro

(HILST, 2017, p. 217) 


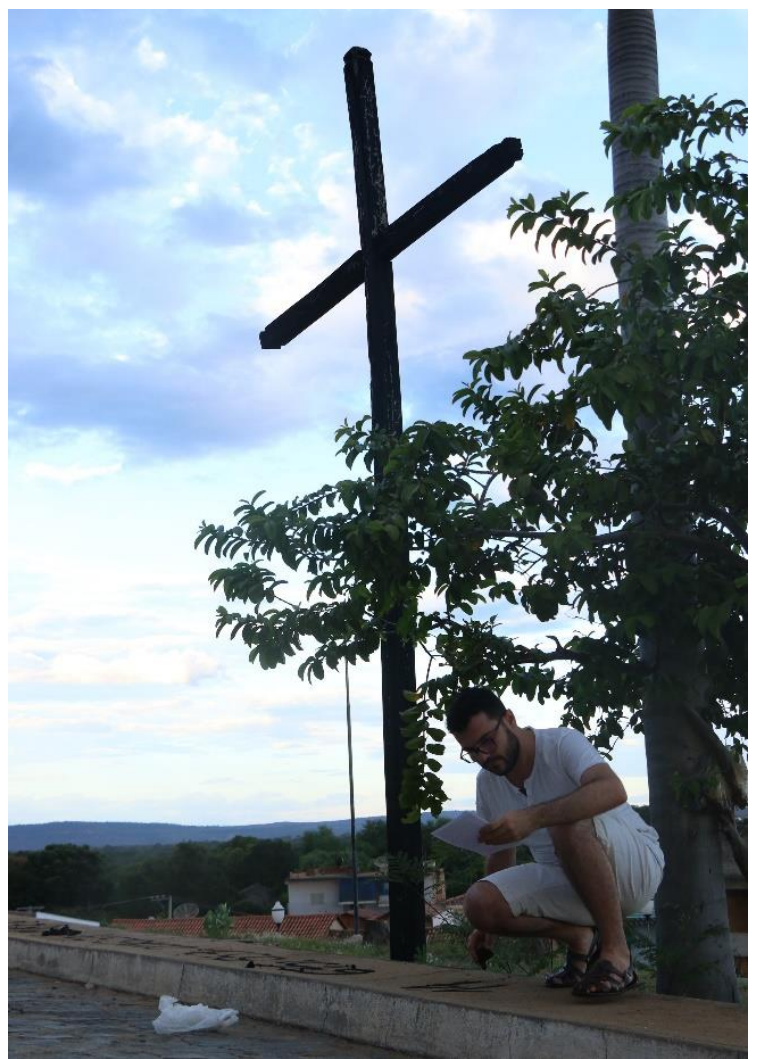

Figura 2 - Tiago Bassani, Me convém lembrar, 2019 - Fonte: Arquivo do autor - Foto: Cirlla Machado
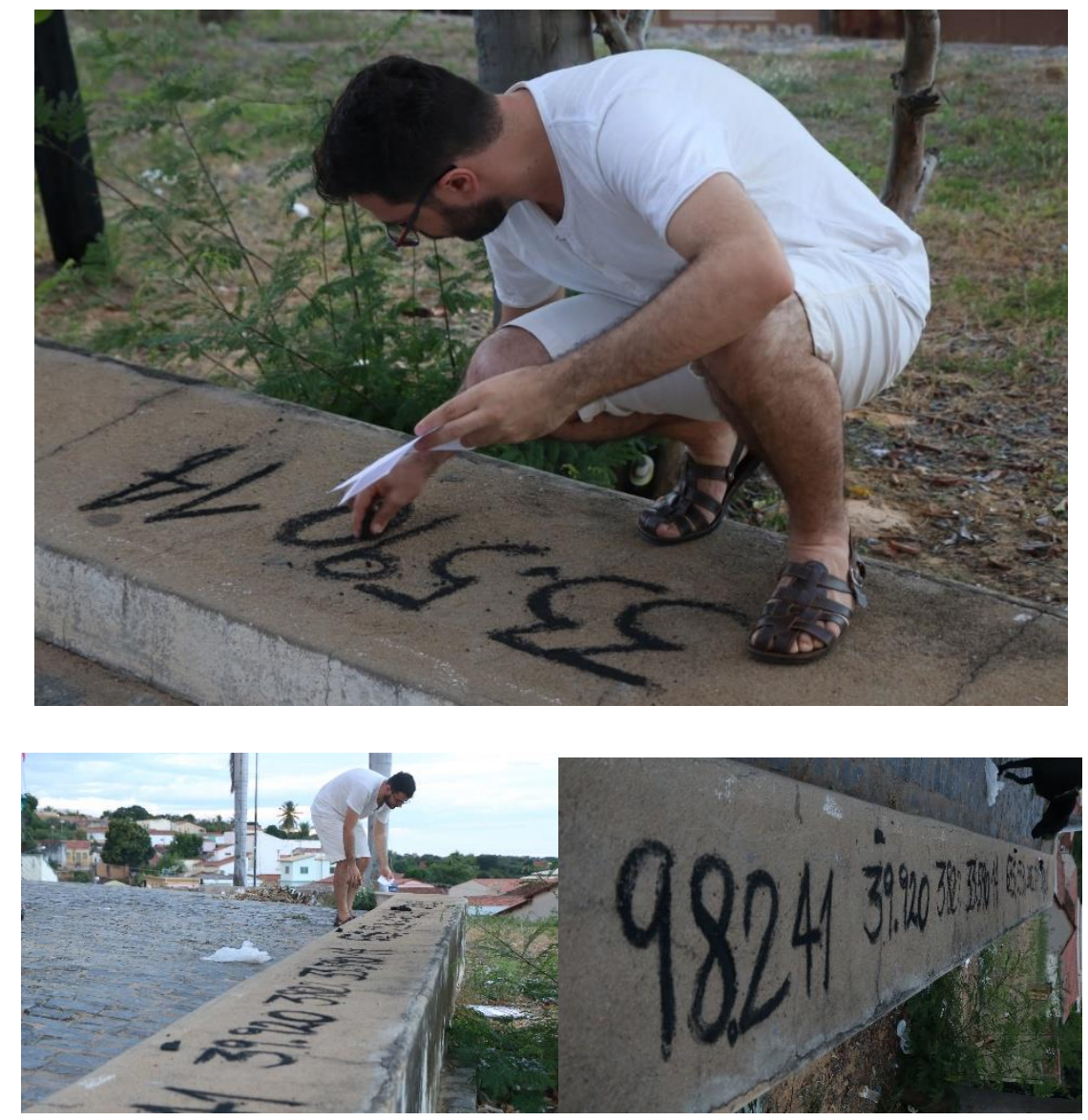

Figura 3 - Tiago Bassani, Me convém lembrar, 2019 - Fonte: Arquivo do autor - Foto: Cirlla Machado 
Ao inscrever o último número no chão, levanto-me limpando as mãos cheia da fuligem do carvão na camisa branca e encerro a ação.

\section{Texto, objeto e palavra}

Nesta ação encontravam-se três objetos: o livro, a folha de papel e o carvão vegetal. A leitura do trecho do livro abria os trabalhos e instaurava uma situação a partir do texto, a folha de papel inscrita com os índices e números das mortes pela violência relacionava-se com o trecho lido. Um punhado de carvão vegetal, que já havia sido depositado na calçada embaixo do cruzeiro, dava forma as palavras que eram inscritas no chão.

Esses materiais me forneciam subsídio para acionar as potencialidades da performance. O livro e seus escritos, a priori, ofertava-me a possibilidade de abertura para as relações que se tramariam posteriormente e incitava a ação por intermédio das palavras contundentes contidas na obra crítica de Galeano.

A folha inscrita com os dados da violência retirada de dentro do livro apontava um tipo de apoio documental, no qual o números das mortes violentas se sustentavam. Ela continha um levantamento que precedia a ação, um estudo sobre o assunto que se fez previamente.

O carvão, como um dos objetos significantes, oriundo de uma carbonização serve também como inserção de uma vestígios e sinais a fim de marcar uma parte do processo que é inscrito. Ele possui uma porosidade que operava sobre uma inscrição forte e densa em contato com o cimento do chão da calçada.

O espaço no qual a ação aconteceu marca simbolicamente um lugar, que pode ser incorporado com o conteúdo da ação e seu propósito. Ele se integra com o todo, uma vez que, tempos atrás o espaço da igreja fora destinado para servir como cemitério.

Penso que, neste sentido, a performance começa a ser elaborada a partir de um estímulo a respeito de um fenômeno, neste caso o contato com as informações sobre as mortes pela violência. Quando uma ocorrência nos afeta, ela pode se dar por intermédio da leitura, correlacionando posteriormente com todos os elementos do trabalho. Circunstância que configura na ação um tempo passado, presente e futuro, apresentando as transmissões que se tem no despertar para ação, no desenrolar dela e nos desdobramentos deste processo, como a reflexão que aqui apresento. Tudo isto é performance.

Deste modo continuado este texto se apresenta como desdobramentos de um trabalho sobre o qual o pensamento e a escrita o mantém ativado, presentes numa relação entre tempos e ainda os vínculos entre a performance, os objetos e o texto, na qual ao mesmo tempo que oferece um tipo de estrutura para uma ação, que tem como base também questões sociológicas e históricas oriundas de políticas adotadas ao longo do tempo que demonstraram ineficiência diante as necessidades de uma comunidade e suas relações sociais. Tudo isto pode ser performance.

Ao proferir e inscrever na calçada os números da violência no país e na região, percebi que as pessoas que estavam presentes na ação se assustavam com os dados nos seus altos índices e números. Com tal reação me ocorreu em pensar como nos colocamos distanciados de um determinado contexto, nos apartando de uma questão muito presente numa comunidade e como não as relacionamos com determinadas referências que podem gerar rebatimentos.

Neste caso, o excerto do texto do Galeano junto dos dados das mortes por violência, ligado à ação, reflexão e indagação, naquele espaço específico, geraram uma confluência de sentidos que ressoaram na reação de alarme percebida no comportamento de alguns participantes. Portanto, a conjunção de elementos de uma ação podem ser potencializadores de discursos e de significados.

Por mais complexa - e neste caso violenta - que seja o extrato social, não se pode afastarse do lugar (território) que se vive e interage, onde se experimenta a vida cotidianamente. Nesse 
sentido, pode-se compreender a necessidade de atuar politicamente a partir de práticas, artísticas, ressaltando a importância da atuação do artista como um propulsor de questões geradoras capazes de engendrar indagações, bem como seus elementos que podem subsidiar, sua ação e consequentemente sua repercussão.

\section{Tudo é permitido, mas nem tudo me convém}

O que me convém lembrar?

Toda vez que tal questão surge me apego na ideia de que lembrar pode estar atrelado no meu imaginário - e também de algumas outras pessoas - a um acontecimento que pode ser considerado bom.

Dos acontecimentos ruins eu não quero nem saber!

Assim, a rememoração de alguns fatos pode dar um gosto saudosista de um passado que queremos guardar sempre como bons olhos. Porém, nem tudo são flores, nem mesmo as nossas memórias. Deste modo, trago por este motivo um fenômeno social que habita todo o território onde vivemos que é preciso ser lembrado.

Recorro a Paul Ricoeur que nos indicar que "não temos nada melhor que a memória para significar que algo aconteceu, ocorreu, se passou antes que declarássemos nos lembrar dela [...] (2007, p. 40). Deste modo, para termos memória é preciso acionar, performar e anunciar aos que puderem nos ouvir para que possamos sempre nos lembrar operando, neste caso, com texto, objeto e palavra. Por isso, me convém lembrar dos mortos que desconheço.

Peço licença, mas não posso furtar-me de tratar um acontecimento social que age sobre toda a ação. Preciso tratar dele aqui.

Deste modo, tomando uma ação que traz à tona um fenômeno social, junto de informações e referencial como fomentadores de discursos no contexto da arte, compreendo uma condição da produção de arte e sua inserção como forma de ser/estar atuante entendendo quais são seus meios e seus agentes ativadores.

Junto de tal apontamento, parto do princípio de uma amálgama das características que podem aproximar da máxima da estratificação social e da violência, que também pode ser fruto da má distribuição de renda, que sempre quiseram justificar atrelando a ideia de que existem muitos, ou seja, encontram-se comunidades muito populosas, a fim de "justificar a desigual distribuição de renda entre os países e classes sociais, quer convencer os pobres de que a pobreza é consequência dos filhos, que não evitam" (GALEANO, 2017, p. 23). Reforçando a ideia de que a pobreza e a marginalidade podem ser causadas pelo próprio empobrecido. Analogicamente falando a violência seria culpa dos próprios violentados.

Essa é uma oposição de forças entre os que mantém o poder e os que são oprimidos por ele. A ação de opressão se estende dentro do nosso próprio território tem desdobramentos nas afirmações de Paulo Freire (1987), no qual o oprimido pode tomar lugar de opressor por consequência da sua condição.

Raros são os camponeses que, ao serem "promovidos" a capatazes, não se tornam mais duros opressores de seus antigos companheiros do que o patrão mesmo. Porder-se-ia dizer - e com razão - que isto se deve ao fato de que a situação concreta, vigente, de opressão, não foi transformadora. E que, nesta hipótese, o capataz, para assegurar seu posto, tem de encarnar, com mais dureza ainda, a dureza do patrão. (FREIRE, 1987, p. 18).

Talvez isso explique que a situação social possa ser geradora de violências entre os membros de uma mesma comunidade, referindo-se as violências sofridas nos territórios latinos 
americanos e no Brasil que são advindos das violência sistêmica instauradas em meio a um mesmo povo. Galeano (2017, p. 18) aponta essa situação dentro do próprio território gerando impetuosa disputa numa arbitrariedade "[...]dentro da América Latina, a opressão de países pequenos pelos maiores seus vizinhos, e fronteiras dentro de cada país [...]".

A partir da questão apresentada me disponho a pensar sobre o papel da arte nesta perspectiva e percebo, a princípio, que no campo da arte contemporânea a combinação entre arte e política tem sido o caminho adotado pelos artistas para discutir os problemas sociais, bem como a violência. Walter Benjamin (1987) já discorre sobre as transformações pelas quais a arte passa desde a possibilidade reprodutiva, na qual ela perde sua áurea e se integra mais com as condições da sociedade, tendo em vista novas questões políticas.

A integração de campos que coloca a arte, as condições sociais e consequentemente a política em consonância podem ser utilizadas de diversas maneiras para direcionar uma intenção, pois, [...] "a atividade artística sempre foi requisitada pelo poder para dar visibilidade aos conceitos que lhes servem de princípios" [...] (CAUQUELIN, 2005, p. 162). Destarte podemos entender a mudança de um estado no qual a arte serve à uma política e a outra na qual a arte se serve da política para implementar seu discurso. Um maneira articulada e complexa, porque quando o poder se serve da arte para dar visibilidade, apresenta-se num intuito imperativo, já quando ela se serve da política, está aproximada a uma objetivo de manifestação e/ou contraposição.

\section{Relembrando}

Todas as perspectivas trazidas aqui são comprimidas num texto, porém o sentimento que posso ter a partir desta ação e reflexão, transbordam. Pensamos num alinhavo entre elementos de uma ação (objetos, textos, palavras, fenômeno social) numa convergência para que eles conferisse à ação uma possibilidade de interpretação e percepção de um contexto social.

De maneira crítica entramos vagarosamente nas questões sociais que cerceiam o assunto, mas que inundam a ação como um todo. Também esse modo de lidar com o fazer artístico não prega um axioma de como confluir os elementos para uma ação. Dirijo aqui uma perspectiva a partir de um ponto de vista de uma experiência, e elas são múltiplas e variadas.

Interessou-me compreender as relações ativadoras num trabalho em arte tendo em vista suas relações entre o meio e o processo de produção, sem deixar de lado as propriedades que envolvem um modo de fazer integral num caminho que pode tomar corpo o trabalho e seus elementos. Consignado a este pensamento está a concepção de que o trabalho pode emanar as questões trazidas posteriormente, ele pode vir antes e dar subsídio para uma compreensão e um modo de pensar e produzir conhecimento.

\section{Referências}

ATLAS DA VIOLÊNCIA 2019. Organizadores: Instituto de Pesquisa Econômica Aplicada; Fórum Brasileiro de Segurança Pública. Brasília: Rio de Janeiro: São Paulo: Instituto de Pesquisa Econômica Aplicada; Fórum Brasileiro de Segurança Pública. Relatório disponível em: <https://biblioteca.ibge.gov.br/visualizacao/periodicos/135/rc_2017_v44_informativo.pdf >

Acesso em: 25 mar. 2019.

BENJAMIM, Walter. Obras escolhidas. Magia e técnica, arte e política. São Paulo: Editora Brasiliense, 1987. 
CAUQUELIN. Anne. Arte Contemporânea: uma introdução. São Paulo: Martins Fontes, 2005.

FREIRE, Paulo. Pedagogia do Oprimido. Rio de Janeiro: Paz e Terra, 1987.

GALEANO. Eduardo H. As veias abertas da América Latina. Porto Alegre: L\&PM, 2017.

HILST, Hilda. Da poesia. São Paulo: Cia das Letras, 2017.

RICCEUR, Paul. A memória, a história, o esquecimento. Campinas: Editora da Unicamp, 2007.

TAYLOR, Diana. O arquivo e repertório: performance e memória cultural nas Américas. Belo Horizonte: Editora UFMG, 2013.

\section{Sobre o autor}

Tiago Bassani é Artista Visual, Professor do curso de Artes Visuais da Universidade Federal do Oeste da Bahia. Professor Formador II da Universidade Estadual da Bahia (UNEB-CAPESPARFOR). Faz um Doutorado em andamento em Artes Visuais (IA-UNICAMP). É Mestre em Artes Visuais e Especialista em Artes Visuais, Intermeios e Educação, Bacharel e Licenciado em Artes Visuais, títulos pela Universidade Estadual de Campinas (UNICAMP). Desenvolve trabalhos em desenho, performance, vídeo, objetos e instalação.

E-mail: tiago.bassani@ufob.edu.br. 